\title{
Organic dust toxic syndrome among farmers
}

\author{
ANNA RASK-ANDERSEN \\ From the Departments of Clinical Physiology and Occupational Medicine, University Hospital, S-751 85 \\ Uppsala, and the National Institute of Occupational Health, S-171 84 Solna, Sweden
}

\begin{abstract}
Clinical symptoms and exposure conditions were investigated in 80 farmers with organic dust toxic syndrome, defined as the occurrence of febrile reactions after exposure to organic dust in subjects with no evidence of allergic alveolitis. The material was compiled from a field study of febrile reactions in the farming community and the diagnosis was based on interviews performed by physicians. Of the 75 men (mean age 44) and five women (mean age 39), only $13 \%$ of the men and none of the women were current smokers. One attack had been experienced by $44 \%$ and the remaining subjects had had two or more attacks, often several years apart. The duration of symptoms was 24 hours or less in $46 \%$ of the farmers and in $95 \%$ of the cases the symptoms lasted less than one week. The attacks were most common in the autumn and were usually provoked by handling grain ( $80 \%$ of the farmers with organic dust toxic syndrome). Other causes were hay, straw, wood chips, and silocapping material. The material was usually described as extremely mouldy and the episodes were usually provoked by unusual work tasks such as cleaning grain bins or removing mouldy feed. Twenty three farmers had consulted physicians: five of nine examined during symptoms had slightly abnormal chest radiographs and two of four examined had decreased arterial oxygen tension. Spirometry performed during a symptom free interval was normal.
\end{abstract}

Agricultural dust consists of a complex mixture of several different components, many of which may cause pulmonary disease. ${ }^{1}$ Inhalation of dust from mouldy material can give rise to allergic alveolitis, ${ }^{2}$ with an inflammatory reaction in the lung parenchyma and infiltration of inflammatory cells in the alveolar membrane. This in turn may lead to impaired gas exchange, resulting in a decrease in $\mathrm{PaO}_{2}$ (arterial oxygen tension) and radiographic lung changes. For a diagnosis of allergic alveolitis to be made, several criteria have to be fulfilled. ${ }^{3}$ When strictly defined, allergic alveolitis is an unusual disease. ${ }^{45}$ Nevertheless, after exposure to mould every tenth farmer has experienced symptoms with fever, resembling those that occur in the acute form of allergic alveolitis but with no other signs of allergic alveolitis. ${ }^{56}$ Several different names have been suggested for this type of febrile attack, including atypical farmer's lung, ${ }^{7}$ precipitin negative farmer's lung, ${ }^{8}$ and pulmonary mycotoxicosis.' Similar episodes have been found to occur in several different environments-for instance, in grain elevators ${ }^{10}$ and sewage treatment plants, ${ }^{11}$ and after unloading silos. ${ }^{12}$ At a symposium in 1985 it was proposed that this disorder should be referred to as organic dust toxic syndrome (ODTS), ${ }^{13}$ even though it is still not established that the syndrome is of a toxic

Accepted 14 March 1988 nature. Allergic alveolitis differs in several respects from ODTS. For instance, ODTS in general causes no permanent impairment to lung function ${ }^{6}$ and the patients quickly improve without treatment. Nevertheless, there is reason to draw attention to this condition as it is important to differentiate it from allergic alveolitis. Otherwise the patient may possibly be subjected to unnecessary, prolonged cortisone treatment with its inherent risk of side effects or the farmer may be advised to change his occupation. No systematic description of ODTS in farming has been published. The aim of the present study was to determine the nature of the typical symptoms and clinical course in ODTS among farmers and to elucidate the question of what type of exposure and which work tasks in farming give rise to the disorder.

\section{Material and methods}

In 1982 a questionnaire was sent to 6267 farms in three counties in central Sweden. Responses were obtained from $72 \%$ of the farms. To evaluate the characteristics of the non-responders, 98 of a random sample of $\mathbf{1 0 0}$ non-responding farms were reached by telephone and the farmers were interviewed. The responses to the questionnaire between the non-responders and the responders did not differ significantly and therefore no corrections were made for non-responders. 
According to the responses to the questionnaire the farmers were selected for an interview and other investigations. All those who had reported medical treatment for farmer's lung or other diseases related to exposure to mould were invited to attend. Half the farmers who had reported a febrile reaction related to work during the week preceding the mailing of the questionnaire, $18 \%$ of those who had reported either febrile or airway obstructive symptoms, $5 \%$ of those who reported other airway symptoms, and $4 \%$ of those who had no reported respiratory symptoms were also invited.

Altogether 390 farmers were interviewed (for further details, see Malmberg ${ }^{5}$ ). The interviews were performed by physicians who were well acquainted with the occupational hazards in farming. Blood samples were taken to determine precipitating antibodies to microbial antigens and total immunoglobulin E concentration (IgE). The presence of precipitating antibodies was investigated against 11 antigens by the immunodiffusion method, the so called double-diffusion-in-gel method of Ouchterlony. ${ }^{14}$ Serum total IgE concentrations were determined with the Phadebas, IgE, PRIST-test (Pharmacia diagnostics, Uppsala). A skin prick test was performed, using standard allergens, and a simple spirometric investigation with a wedge type spirometer (Vitalograph) was carried out.

Two independent investigators evaluated the results of the interviews. ODTS was diagnosed if the subject was not considered to suffer from allergic alveolitis or any systemic or infectious disease but had a history of a febrile reaction that had had its onset a few hours after exposure to organic dust. Only those who had had severe or moderate reactions were included in the study so that the relation between the exposure and the manifestations of the disorder could be considered probable. Eighty subjects were diagnosed as having ODTS and analysed further regarding symptoms and exposure conditions. If the farmer had consulted a doctor on account of ODTS the medical records were studied. In those cases where the farmer had undergone chest radiography this was reviewed by a specialist in pulmonary medicine.

Of the interviewed farmers, 183 had no airway symptom. Some of the results of the investigations in the ODTS group are compared with the results in this group.

\section{Results}

SEX, AGE, AND SMOKING HABITS

Of the 80 subjects ( 75 men, five women) the mean age of the men was 44 and of the women 39 . Of the men, $72 \%$ were non-smokers, $13 \%$ smokers, and $15 \%$ exsmokers. All five women were non-smokers. There was a significantly lower proportion of smokers $(13 \%$

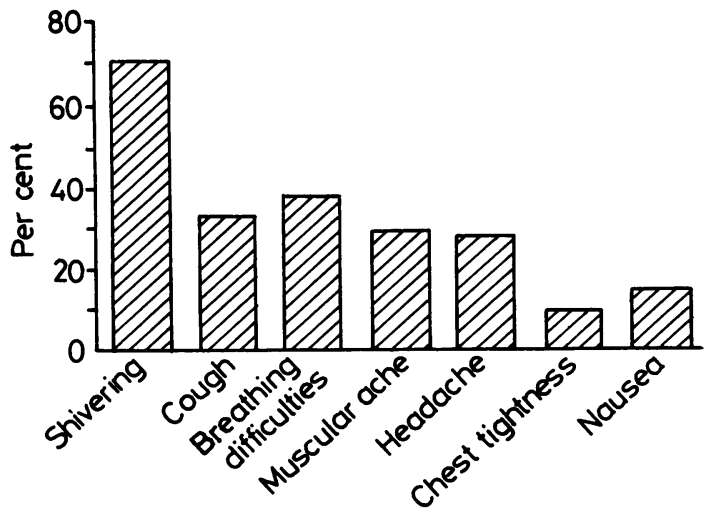

Fig 1 Symptoms in organic dust toxic syndrome.

$v 23 \% ; \mathrm{p}<0.05$ ) among the 80 farmers with ODTS than among the 183 farmers without ODTS or other airway symptoms interviewed on the same occasion.

\section{SYMPTOMS}

All subjects reported fever as the predominating symptom. Just over $25 \%$ of the subjects had taken their temperature during an episode and on average the temperature was $39 \cdot 4^{\circ} \mathrm{C}$. The highest temperature observed was $41^{\circ} \mathrm{C}$. Almost $66 \%$ reported chills as one of the symptoms. Difficulty in breathing was noted in $37 \%$. Thirty three per cent had suffered from cough, one third with exporation. Aching muscles or joints or body aching had been experienced by $29 \%$ of the farmers, and $28 \%$ had had headache. Other, less common symptoms were nausea $(14 \%)$ and chest tightness $(9 \%)$ (fig 1). A general sensitivity to dust, with readily induced cough some time after the attack, occurred in some cases.

DEGREE OF SEVERITY, NUMBER OF ATTACKS, TIME

In $90 \%$ of the cases the symptoms were so severe as to necessitate bed rest for at least a day. Less than half the

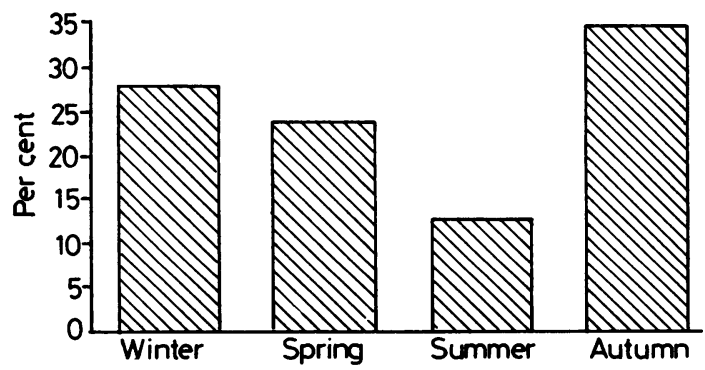

Fig 2 Seasonal variation of organic dust toxic syndrome. Ordinate: number of patients as percentage of total number. Each patient is represented by his or her latest attack.

Investigation period: April to June. Only one third of patients had had an attack during year preceding investigation day. 
subjects had had one and one third had had two to four attacks. One fifth reported more than four attacks. The interval between the attacks was often several years. One third of the farmers had experienced symptoms during the year preceding the interview. About one third had had attacks within five years before that and the remaining third had had their last attack more than six years before the interview. The attacks most commonly occurred during the autumn (fig 2).

\section{DURATION OF EPISODES}

In $40 \%$ of the cases the duration of the episode was about 24 hours and in an almost equal number of cases it was two to three days. In $6 \%$ of the cases the duration was less than 24 hours. Fourteen per cent of the farmers had had an attack that lasted between five days and up to one week, and $5 \%$ had had one that lasted more than one week.

\section{PRESENT SYMPTOMS}

In $35 \%$ of the $56 \%$ suffering from cough, it was occupationally induced. All the $10 \%$ fulfilling the MRC criteria for chronic bronchitis were nonsmokers. Abnormal dyspnoea on effort was experienced by $35 \%$ and $26 \%$ were troubled by wheezing in the chest; $14 \%$ of the latter considered this to be related to working in a dusty environment. Three per cent had asthma requiring medical treatment. Often different combinations of symptoms occurred. Only $40 \%$ of the farmers with ODTS were completely free from airway symptoms even though most of the farmers had had their attacks several years previously. Smokers or ex-smokers did not report a higher frequency of symptoms at the time of the interview than non-smokers. There was a slightly higher proportion of farmers with current symptoms from the airways among those who had had three or more attacks of fever than among the farmers with a history of one or two attacks. On the other hand, the current symptoms showed no relation to the period that had elapsed since the last episode of fever.

\section{MATERIALS AND WORK TASKS}

Most farms were dairy farms run by the farmers, often with the help of their wives. The farmers were usually handling hay, grain for cattle-feed, and straw for bedding.

Eighty five per cent of the farmers with ODTS had themselves noted that the material they worked with before the attack was clearly mouldy. Usually some sort of problem in the handling of the material had resulted in mould growth. In most cases it was unusual work tasks with extreme exposure to dust: $75 \%$ of the farmers had had episodes of fever after handling grain. About $15 \%$ of the patients had had a reaction after having worked with hay and $10 \%$ each after work with straw, silage, and wood. The grain handling task most commonly inducing episodes of fever was grain shovelling, usually with the aim of getting rid of the mouldy material as cows become ill after eating mouldy grain. Some had re-shovelled the grain to dry it. Just under one third of the reactions had occurred after preparing for the next harvest by cleaning corn driers and bins where mouldy grain remained from the previous season. Some farmers had suffered a reaction after crushing grain, and $8 \%$ had become ill after threshing with a stationary threshing machine indoors in a barn, a method used before the modern combine harvesters were introduced. In general the grain was dried with a cold air drier. The reason why the stored grain became mouldy was insufficient drying, caused by high content of water in the grain due to the weather, an unusually large harvest, or during storage-for example, as a result of a leaking roof or penetration of moisture through the walls. In the hard climate that prevails in parts of the region studied it may even snow during the grain harvest. The development of mould can begin during the autumn and remain dormant during the winter because of freezing before increasing rapidly during warm early spring days.

Four farmers had episodes after unloading a silo, two on the same occasion. Otherwise there were reports of eight occasions when two people working together had become ill: on four the farmers had been working with mouldy grain, on two with mouldy silage after uncapping a silo, and on two with mouldy wood chips. The attacks of fever after handling hay were noted in equally large proportions in connection with loading hay, handling mouldy hay, and threshing hay for hayseed. In the last case the harvested hay is left in a barn over the winter to be threshed in the spring and readily becomes mouldy.

Episodes of fever after handling mouldy grain occurred after breaking open large bales of straw, distributing straw for bedding, or shovelling straw.

In most cases of attacks of fever that were suspected to be due to mouldy wood the farmer had been working with mouldy wood chips. There was one case of illness associated with work in a trimming department in a sawmill. In all episodes the pattern of symptoms was similar, irrespective of what material had given rise to the attacks.

MEDICAL CARE

Twenty three farmers had consulted a doctor on account of ODTS, one of them only by telephone (table). In three cases the medical records could not be found despite repeated attempts. About half the farmers had consulted a general practitioner, whereas the others had attended a department of infectious diseases, internal medicine, or pulmonary medicine. Seven patients were referred to a department of 
Characteristics and clinical findings in patients with organic dust toxic syndrome (ODTS)

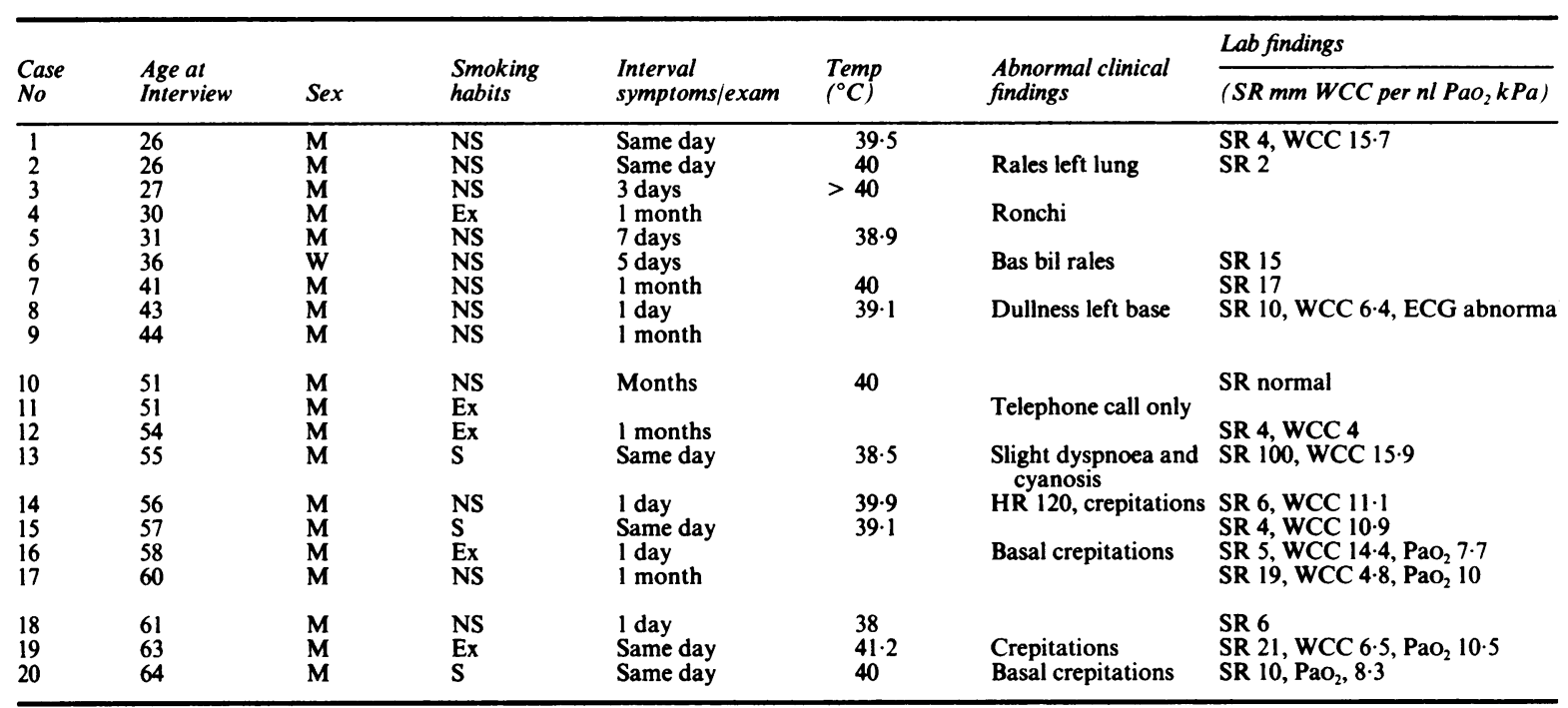

CIE = Counterimmunoelectroforesis.

ID = Immunodiffusion (double-diffusion-in-gel method of Ouchterlony ${ }^{14}$ ).

pulmonary medicine. Ten patients consulted a doctor within 24 hours of the onset of the acute episode. The other patients had consulted a doctor at varying times after the acute symptoms, from three days to some months.

In nine patients there were abnormal clinical findings. The white cell count was measured in ten patients; in six a leucocytosis and an increase in the number of segmented white cells were found. All these patients were examined within 24 hours of the onset of acute symptoms. $\mathrm{PaO}_{2}$ was determined in four patients and two showed values of $7 \cdot 7$ and $8.3 \mathrm{kPa}$ respectively.

Eighteen patients had undergone chest radiography. In nine the radiography was performed during the acute stage of the disease. In this subgroup three radiographs were normal; five had minor abnormalities such as slight streakiness, and one had large hilar shadows and sarcoidosis was suspected. His febrile attack after exposure to mould, however, did not differ from the others. In nine patients the chest radiograph was performed at varying times after the acute episode, from a week to some months. One patient who was given a diagnosis of cardiac decompensation on radiographic grounds died a few years later from myocardial infarction. Precipitins were measured in six patients, all were positive. In four the counterimmunoelectrophoresis method was used, which has since been shown to be much too sensitive. ${ }^{6}$ In the other two cases a method with lower, more adequate sensitivity was used, an immunodiffusion test, also known as the double-diffusion-in-gel method of Ouchterlony. ${ }^{14}$
The patients were diagnosed as having allergic alveolitis, or farmer's lung, or what was called a hypersensitive reaction to mould. Even though it was realised that the condition was associated with mould, seven patients were nevertheless treated with antibiotics. In one patient (case 8 , table) cardiac involvement was suspected on account of ST changes on an ECG. Symptoms and exposure were typical of ODTS, however, and subsequent investigations did not support a cardiac cause of the symptoms.

RESULTS OF PRICK TESTS, TOTAL IgE, PRECIPITIN TESTS, AND SPIROMETRY AT INTER VIEW

Twenty three per cent of the patients had a positive skin prick test and in $15 \%$ precipitating antibodies were present. The mean total IgE value was $33 \pm 41$ $\mathrm{kU} / \mathrm{l}$. These results did not differ significantly from those in the group of farmers without airway symptoms who were interviewed at the same time as the group with ODTS. Nor was any difference noted between the groups regarding the pulmonary function as assessed by spirometry. ${ }^{5}$

\section{Discussion}

It is common for farmers to suffer from episodes of ODTS. Despite its benign nature, the symptoms may be severe, with high fever and a need for bed rest on repeated occasions. This is troublesome for farmers who usually have no deputy to take over the daily supervision of the animals.

There is no reason to believe that sex or age 


\begin{tabular}{|c|c|c|c|c|c|}
\hline$\frac{x \text { Ray findings }}{(A=\text { acute stage })}$ & $\begin{array}{l}\text { Precipitin } \\
\text { test }\end{array}$ & Spirometri & Treatment & $\begin{array}{l}\text { Hospital stay } \\
\text { (days) }\end{array}$ & $\begin{array}{l}\text { Duration of } \\
\text { illness (days) }\end{array}$ \\
\hline $\begin{array}{l}\text { Normal (A) } \\
\text { Diffuse streakiness left base (A) } \\
\text { Normal } \\
\text { Normal } \\
\text { Normal }\end{array}$ & Pos (CIE) & & $\begin{array}{l}\text { Erythromycin } \\
\text { Erythromycin } \\
\text { Cortisone } \\
\text { Penicillin }\end{array}$ & $\begin{array}{l}5 \\
4\end{array}$ & $\begin{array}{l}5 \\
4 \\
5 \\
2-3 \\
7 \\
7\end{array}$ \\
\hline $\begin{array}{l}\text { Large hilar shadows (A) } \\
\text { Lamilar atelectasis left lung (A) } \\
\text { Possible nodulations right base. Poor } \\
\text { technical quality }\end{array}$ & $\begin{array}{l}\text { Pos (CIE) } \\
\text { Pos (CIE) }\end{array}$ & Normal & $\begin{array}{l}\text { Penicillin, cough mixture } \\
\text { Obs at int care unit. Myocarditis }\end{array}$ & & $\begin{array}{l}4-5 \\
4 \\
1-2\end{array}$ \\
\hline Normal & & & $\begin{array}{l}\text { Chloramphenicol } \\
\text { Sulpha, cough mixture }\end{array}$ & & 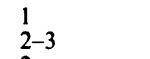 \\
\hline $\begin{array}{l}\text { Cardiac decompensation } \\
\text { Slight streakiness right base (A) }\end{array}$ & Pos (CIE) & & & 3 & $2-3$ \\
\hline $\begin{array}{l}\text { Normal (A) } \\
\text { General nodulations, basal streakiness (A) } \\
\text { Slight nodulations, Slight streakiness left lung (A) }\end{array}$ & Pos (ID) & $\begin{array}{l}\text { Normal. Closing } \\
\text { volume increased }\end{array}$ & Terbutaline, cough mixture & $\begin{array}{l}2 \\
1\end{array}$ & $\begin{array}{l}2 \\
1 \\
2-3\end{array}$ \\
\hline $\begin{array}{l}\text { Normal } \\
\text { Bilateral pleural plaques } \\
\text { Normal (A) } \\
\text { Normal }\end{array}$ & Pos (ID) & $\begin{array}{l}\text { Slightly obstructive } \\
\text { Obstructive diff } \\
\text { cap normal }\end{array}$ & $\begin{array}{l}\text { Cortisone } \\
\text { Penicillin, cortisone, terbutaline } \\
\text { Penicillin }\end{array}$ & $\begin{array}{r}14 \\
4 \\
3\end{array}$ & $\begin{array}{l}1 \\
2-3 \\
14\end{array}$ \\
\hline
\end{tabular}

influences the reaction to exposure to mould. ODTS can occur at as young an age as allergic alveolitis. ${ }^{15}$ Some of the patients in our study had had episodes of fever in their early teens after using a stationary thresher. Two subjects admitted to the hospital were 17 year old boys who were pupils at an agriculture school and became ill after unloading a silo with mould covering the grain. Only five women were among the 80 farmers with ODTS, but the relative predominance of men in this group may reflect the fact that men more often than women carry out physically heavy jobs such as shovelling out mouldy grain. This result may be compared with the finding in Finland that women are afflicted with allergic alveolitis more often than men ${ }^{4}$; in Finland the women are responsible for feeding the cattle. There were significantly fewer smokers among the farmers with ODTS compared with the farmers without ODTS or other airway symptoms. Even among patients with allergic alveolitis a lower frequency of smokers has been noted,$^{16}$ which could be due to differences in immune defence between smokers and non-smokers.

The symptoms reported by the farmers in the present study are in accordance with those noted in farmers after uncapping silos. ${ }^{12}$ The clinical findings of those who sought medical care also showed the same pattern as in silo unloading disease. Thus a leucocytosis with a left shift was found. Some cases had crepitations and minor changes in their chest radiographs. The symptoms and the interval between the exposure and onset are similar to those in the acute form of allergic alveolitis but ODTS is of short duration and as a rule severe dyspnoea is not a dominant feature.

The increased general sensitivity to dust after an episode, as reported by the ODTS group, could be equivalent to the bronchial hyperreactivity that is found in patients with allergic alveolitis. ${ }^{17}$ Among farmers who had had attacks of ODTS, only $40 \%$ were completely free from symptoms of the respiratory tract at the time of the interview; however, extensive investigations have showed no effects in respiratory function, gas exchange, or exercise capacity in farmers who have experienced attacks of ODTS. ${ }^{6}$

ODTS does not constitute a new problem in farming, although one third of the farmers reported an attack during the year preceding the interview. This should not be interpreted as an evidence of increasing incidence of these problems but may rather reflect increased awareness of occupational hazards and memory lapses.

ODTS in farmers has previously been described in association with the unloading of silos. In the present study only four of the cases were associated with this task. Instead most cases were provoked by exposure to mouldy grain, probably because grain easily becomes mouldy as it is often harvested under unfavourable conditions, with rain and even snow. It was often difficult to get the grain sufficiently dry, even though it was usually dried using ambient air driers. In grain elevator workers $6-33 \%$ have reported grain fever. ${ }^{18}$ In those reports, however, there is no information as to whether the grain causing grain fever was mouldy or not. In the present study the grain causing ODTS was 
often extremely mouldy.

Hay can most often be harvested in good weather and drying is usually effective, which means that problems with mould are not so pronounced. Regarding the handling of straw, new methods such as the use of large bales have led to mould developing. Silage treatment is one way of avoiding mould but unfortunately mould in the silo cover is not unusual. This may be avoided by not using organic material on tarpaulins as a silo cover.

The use of wood chips was introduced with the aim of saving oil after the energy crisis in 1973. Burning of wood chips for heating purposes quickly became popular in the study region, as the farming estates often include forests. Here we see an example of how new technology may cause problems. The error that many have made has been to chop up much too large piles of damp wood.

ODTS may, in principle, occur at any time of the year. The fact that several people become ill after working at the same job would seem to indicate that it will occur only if the exposure is sufficiently high. Depending on when the farmer chooses to do this work, the attack will occur if he is sufficiently exposed. This may be compared with allergic alveolitis which as a rule occurs only when the animals are indoors. ${ }^{19}$ Repeated exposure is necessary for allergic alveolitis to develop which may explain why it is often caused by materials used daily, such as hay, straw, and wood chips.

The group with ODTS did not exhibit a significantly higher frequency of precipitins $(15 \%)$ at the interview than the group of the farmers without ODTS or airway symptoms interviewed on the same occasion. The presence or absence of precipitins is thus not a useful criterion for diagnosing ODTS. In this respect ODTS differs from allergic alveolitis, where a higher frequency of positive precipitins is found. ODTS does not give rise to persistent changes in lung function, which was found not to be impaired in that group.

When selecting for interviews efforts were made to find all cases of allergic alveolitis. All farmers who had had specific medical treatment for diseases caused by exposure to mould were further investigated. Still only 23 farmers with ODTS who had consulted a doctor were found. This should be seen in relation to the fact that the questionnaire was sent to over 6000 farms and the cumulative incidence of ODTS was $6 \%$. Thus it is uncommon for patients with ODTS to seek medical care. That seven of the 23 patients were treated with antibiotics indicates that ODTS is not always fully considered as a diagnostic alternative by physicians in general. Several of the patients with ODTS were considered to suffer from allergic alveolitis and in some cases a change of occupation was discussed, even though the symptoms lasted only a few days. Several investigators have indicated distinct differences between ODTS and allergic alveolitis. ${ }^{72}$ It is important to make a correct diagnosis of ODTS and not to treat it with cortisone as in allergic alveolitis or antibiotics as in infectious disease.

By using optimal farming methods, certain instances of mould formation may be prevented, but mould is probably unavoidable on account of climatic variations. If mould has developed the farmer should use an adequate breathing mask to avoid unnecessary illness.

Sincere gratitude and appreciation are directed to Assistant Professor Gunnemar Stålenheim, Department of Lung Medicine, University Hospital, Uppsala, for reviewing the chest radiographs and to Miss Erna Bengtsson for excellent secretarial help.

Supported by grant $80 / 304$ from the Swedish Work Environment Fund.

\section{References}

1 Donham KJ. Hazardous agents in agricultural dusts and methods of evaluation. Am J Ind Med 1986;10:205-20.

2 Pepys J, Jenkins PA, Festenstein GN, Gregory PH, Lacey ME, Skinner FA. Farmer's lung. Thermophilic actinomycetes as a source of "farmer's lung hay" antigen. Lancet 1963;ii:607-11.

3 Terho EO. Diagnostic criteria for farmer's lung disease. Am J Ind Med 1986;10:329.

4 Terho EO, Heinonen OP, Lammi S. Incidence of clinically confirmed farmer's lung disease in Finland. Am J Ind Med 1986;10:330.

5 Malmberg P, Rask-Andersen A, Höglund A, Kolmodin-Hedman B, Read-Guernsey J. The incidence of organic dust toxic syndrome and allergic alveolitis in Swedish farmers. Int Arch Allergy Appl Immunol 1988;87:47-54.

6 Malmberg P, Rask-Andersen A, Palmgren U, Höglund S, Kolmodin-Hedman B, Stålenheim G. Exposure to microorganisms, febrile and airway-obstructive symptoms, immune status and lung function of Swedish farmers. Scand J Work Environ Health 1985;11:287-93.

7 Jones A. Farmer's lung: an overview and prospectus. Ann Am Conf Gov Ind Hyg 1982;2:171-81.

8 Edwards JH, Baker JT, Davies BH. Precipitin test negative farmer's lung activation of the alternative pathway of complement by mouldy hay dusts. Clin Allergy 1974;4:379-88.

9 Emanuel DA, Wenzel FJ, Lawton BR. Pulmonary mycotoxicosis. Chest 1975;67:293-7.

10 doPico GA, Flaherty D, Bhansali P, Chavaje N. Grain fever syndrome induced by inhalation of airborne grain dust. $J$ Allergy Clin Immunol 1982;69:435-43.

11 Rylander R, Andersson K, Belin L, et al. Sewage worker's syndrome. Lancet $1976 ;$ ii:478-9.

12 Pratt DS, May JJ. Feed-associated respiratory illness in farmers. Arch Environ Health 1984;39:43-8.

13 doPico GA. Health effects of organic dusts in the farm environment. Report on diseases. Am J Ind Med 1986;10:261-5.

14 Belin L. Clinical and immunological data on "wood trimmer's disease" in Sweden. Eur J Respir Dis suppl 1980;107:169-76.

15 Bureau MA, Fecteau C, Patriquin H, Rola-Pleszczynski M, Masse $\mathrm{S}$, Begin R. Farmer's lung in early childhood. Am Rev Respir Dis 1979;119:671-5.

16 Warren CP. Extrinsic allergic alveolitis: a disease commoner in non-smokers. Thorax 1977;32:567-9.

17 Mönkäre S, Haahtela T, Ikonen M, Laitinen LA. Bronchial hyperreactivity to inhaled histamine in patients with farmer's lung. Lung 1981;159:145-51.

18 Becklake MR. Grain dust and health: state of the art. In: Dosman JA, Cotton DJ, eds. Occupational pulmonary disease. Focus on grain dust and health. New York: Academic Press 1980:189-200.

19 Terho EO, Lammi S, Heinonen OP. Seasonal variation in the incidence of farmer's lung. Int J Epidemiol 1980;9:219-20. 